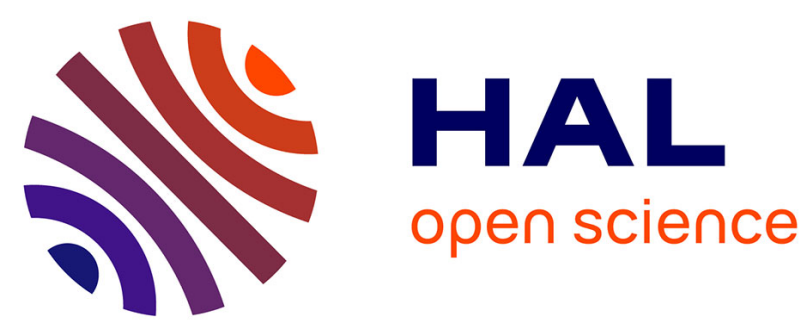

\title{
Musical sonification improves motor control in Parkinson's disease: a proof of concept with handwriting
} Lauriane Véron-Delor, Serge Pinto, Alexandre Eusebio, Jean-Philippe Azulay, Tatiana Witjas, Jean-Luc Velay, Jérémy Danna

\section{- To cite this version:}

Lauriane Véron-Delor, Serge Pinto, Alexandre Eusebio, Jean-Philippe Azulay, Tatiana Witjas, et al.. Musical sonification improves motor control in Parkinson's disease: a proof of concept with handwriting. Annals of the New York Academy of Sciences, 2020, Special Issue: Annals Reports, 1465 (1), pp.132-145. 10.1111/nyas.14252 . hal-02316980

\author{
HAL Id: hal-02316980 \\ https://hal.science/hal-02316980
}

Submitted on 15 Oct 2019

HAL is a multi-disciplinary open access archive for the deposit and dissemination of scientific research documents, whether they are published or not. The documents may come from teaching and research institutions in France or abroad, or from public or private research centers.
L'archive ouverte pluridisciplinaire $\mathbf{H A L}$, est destinée au dépôt et à la diffusion de documents scientifiques de niveau recherche, publiés ou non, émanant des établissements d'enseignement et de recherche français ou étrangers, des laboratoires publics ou privés. 


\title{
Musical sonification improves motor control in Parkinson's disease: a proof of concept with handwriting
}

\author{
Lauriane Véron-Delor, ${ }^{1,2}$ Serge Pinto, ${ }^{2}$ Alexandre Eusebio, ${ }^{3,4}$ Jean-Philippe Azulay, ${ }^{1,4}$ \\ Tatiana Witjas, ${ }^{3,4}$ Jean-Luc Velay, ${ }^{1}$ and Jérémy Danna ${ }^{1}$ \\ ${ }^{1}$ CNRS, LNC, Aix-Marseille Université, Marseille, France. ${ }^{2}$ CNRS, LPL, Aix-Marseille Université, Aix-en-Provence, France. \\ ${ }^{3} \mathrm{CNRS}$, Institut de Neurosciences de La Timone, Aix-Marseille Université, Marseille, France. ${ }^{4}$ Hôpital La Timone, Service de \\ Neurologie et pathologie du mouvement, APHM, Marseille, France
}

Address for correspondence: Lauriane Véron-Delor, Laboratoire Parole et Langage - Aix-Marseille Université/CNRS, 5

Avenue Pasteur, Bouches du Rhône, Aix en Provence 13100, France. lauriane.veron-delor@univ-amu.fr

\begin{abstract}
A growing number of studies postulate the use of music to improve motor control in patients with Parkinson's disease (PD). The effects of music are greatly variable from one individual to the other and do not always reach the expected benefits. This study aimed to optimize the use of music in the management of movement disorders inherent to PD in a handwriting task. We developed and tested musical sonification (MS), a method that transforms in real-time kinematic variables into music. Twelve patients with PD, on medication, and 12 healthy controls were recruited in a pretest/training/posttest design experiment. Three training sessions were compared, for which participants were asked to produce graphomotor exercises: one session with music (unrelated to handwriting), one with MS (controlled by handwriting), and one in silence. Results showed that the performance in training was better under MS than under silence or background music, for both groups. After training, the benefits of MS were still present for both groups, with a higher effect for PD patients than for control group. Our results provide a proof of concept to consider MS as a relevant auditory guidance strategy for movement rehabilitation in patients with PD.
\end{abstract}

Keywords: Parkinson's disease; handwriting; musical sonification; rehabilitation

\section{Introduction}

Although music and rhythm training have been considered as part of rehabilitation alternatives for many years, ${ }^{1}$ these received a growing scientific interest during the last decade. Positive effects of such trainings have been recently demonstrated, ${ }^{2,3}$ supported by solid arguments highlighting the relationship between sound and movement. ${ }^{4}$ Since motor and auditory systems interact, human beings have a spontaneous inclination toward synchronizing their actions with rhythm when listening to music. Beyond auditory information, rhythm represents an external auditory cue allowing for movement guidance and enhancing motor control. ${ }^{5,6}$ Predictive timing may be an intrinsic feature of music that drives rhythmic and metrically organized motor behavior, as a metronome, guiding movements. ${ }^{7,8}$
Auditory cueing as a tool for motor rehabilitation has been particularly explored in patients with Parkinson's disease (PD). ${ }^{9-11}$ For example, recent studies have shown that external rhythmic cueing had beneficial effects on PD axial signs, such as impairment of gait $^{12-14}$ and speech. ${ }^{15-18}$ Regarding distal movements, rhythmic cueing also demonstrated improvements of hand and foot tapping, ${ }^{19}$ and upper-limb freezing. ${ }^{20}$ Neuroimaging studies demonstrated in both healthy subjects and PD patients that the supplementary motor area and basal ganglia were the principal areas involved in self-initiated movements, while the parietal and the lateral premotor cortices, as well as the cerebellum, played a major role in externally cued movements. ${ }^{21-23}$ Consequently, external cueing would activate a brain network involving the cerebellum, in order to compensate for thereduced 
recruitment of the basal ganglia, altered in PD. ${ }^{24,25}$ Nevertheless, such improvement remains very variable, and sometimes opposite, from one patient to the other. ${ }^{12,26,27}$ The main reason is that performing a movement with an external auditory cueing requires both to perceive and synchronize the movement with the cue; and these rhythmic skills might be altered in patients with PD. ${ }^{12}$

Among motor skills, handwriting seems to be particularly vulnerable in PD. ${ }^{28-30}$ Handwriting requires a high level of motor coordination and expertise; it has been described, with drawing, as the most challenging and elaborate fine motor activity. ${ }^{31,32}$ Handwriting impairments that define PD dysgraphia ${ }^{33,34}$ may be partially improved by dopaminergic medication and neurostimulation, ${ }^{35,36}$ as well as behavioral treatments. So far, behavioral studies focused on the use of visual external cueing in order to manage writing size. ${ }^{37-43}$ While Ringenbach et al. ${ }^{38}$ reported a greater effect of auditory feedback than visual external cueing on drawing in PD patients, to our knowledge, no study has focused so far on the use of auditory/music external cueing for the management of PD dysgraphia. Applying auditory information for the rehabilitation of handwriting disorders has mainly been investigated with sonification. ${ }^{44}$ Sonification is a technique of augmented reality that could be defined as the use of nonspeech audio to convey dynamic information. ${ }^{45}$ Digitized handwriting allows us to determine several kinematic "hidden" variables, which inform about the movement generating the trace. Handwriting sonification amounts to transforming some of these hidden variables into auditory information in order to enhance handwriting perception, control, and learning. ${ }^{44}$ Although sonification has demonstrated efficiency for motor rehabilitation, ${ }^{46,47}$ using music in sonification could improve the motivational component for such movement guidance. ${ }^{48,49}$ Emotional features of music can be observed even at the physiological level by modulating muscular afferences. ${ }^{50}$ To sum up, (1) providing supplementary auditory feedback would be a relevant strategy for rehabilitating movement impairment, and (2) providing a musical cueing would further enhance such management. Consequently, combining both methods in musical sonification (MS) would benefit from the advantages of the two strategies. MS consists of enslaving musical sounds to movement in order to convey real-time supplementary information. ${ }^{11}$ Technically, preselected music is modified according to kinematic variables: music is distorted when the movement is too slow. Theoretically, the purpose of MS is both to improve the perception of movement irregularities (when music changes) and to provide auditory guidance (when music does not change). In the case of handwriting, this method changes music as a function of pen movements, like a conductor baton.

Our study aimed to demonstrate the relevance of MS as a potential tool for managing handwriting impairment in patients with PD. Handwriting skills were evaluated under three conditions - silence, background music, and MS in a pretest/training/posttest design. We hypothesized that both background music and MS should lead to better performance when compared with silence, especially in writing frequency. Furthermore, MS should provide, in addition to the auditory cueing, an auditory feedback potentially contributing to enhancing movement performance. Then, we further hypothesized that MS would lead to better performance when compared with background music, especially in writing velocity.

\section{Methods}

\section{Participants}

Twelve right-handed patients with idiopathic PD (60.9 years \pm 8.03 ; four females) and 12 handedness-, age-, and gender-matched controls (60.6 years \pm 8.05 ; four females) participated in the experiment. All patients included did not present any cognitive impairment, confirmed by the Montreal Cognitive Assessment (MoCA $)^{51}$ or the Mattis Dementia Rating Scale (MDRS). ${ }^{52}$ All patients were tested on medication, $2 \mathrm{~h}$ at the most after medication intake, and were clinically evaluated with the motor examination (part III) of the Movement Disorders Society Unified Parkinson's Disease Rating Scale (MDS-UPDRS).$^{53}$ Both PD patients and control participants had normal hearing and normal or corrected-to-normal vision. Exclusion criteria included: medical, psychological, or cognitive history (e.g., language disorders) that would interfere with the study completion. In addition, control participants did not present with any neurological affliction. Before the experiment, participants completed an anamnesis questionnaire, allowing them also to report their musical 
Table 1. Demographics of all participants and clinical information of the PD patients

\begin{tabular}{|c|c|c|c|c|c|c|c|c|c|c|}
\hline & \multicolumn{2}{|c|}{ Age (years) Gender } & $\begin{array}{l}\text { Conditions } \\
\text { order }\end{array}$ & $\begin{array}{c}\text { Musical } \\
\text { environment }\end{array}$ & $\begin{array}{l}\text { MoCA } \\
\text { or } \\
M D R S\end{array}$ & D (years) & $\begin{array}{c}\text { MDS- } \\
\text { UPDRS III } \\
\text { (on-med) LF }\end{array}$ & $(\mathrm{mg})$ & \multicolumn{2}{|c|}{$\begin{array}{l}\text { Symptom } \\
\text { dominance MG }\end{array}$} \\
\hline \multicolumn{11}{|c|}{ Patients with Parkinson's disease } \\
\hline 01 & 61 & $\mathrm{M}$ & $\mathrm{Si} / \mathrm{MS} / \mathrm{BM}$ & $\mathrm{n} / \mathrm{y}$ & 28 & 11 & 12 & 1595 & $\mathrm{R}$ & $\mathrm{y}$ \\
\hline 02 & 60 & $\mathrm{M}$ & $\mathrm{Si} / \mathrm{BM} / \mathrm{MS}$ & $\mathrm{n} / \mathrm{y}$ & 132 & 3 & 7 & 2138 & $\mathrm{~L}$ & $\mathrm{n}$ \\
\hline 03 & 47 & M & $\mathrm{BM} / \mathrm{Si} / \mathrm{MS}$ & $\mathrm{n} / \mathrm{y}$ & 29 & 5 & 5 & 880 & $\mathrm{~L}$ & $\mathrm{n}$ \\
\hline 04 & 48 & M & $\mathrm{Si} / \mathrm{MS} / \mathrm{BM}$ & $\mathrm{n} / \mathrm{y}$ & 144 & 10 & 5 & 1475 & $\mathrm{~L}$ & $\mathrm{n}$ \\
\hline 05 & 65 & $\mathrm{~F}$ & $\mathrm{Si} / \mathrm{BM} / \mathrm{MS}$ & $\mathrm{n} / \mathrm{n}$ & 137 & 6 & 11 & 950 & $\mathrm{~L}$ & $\mathrm{y}$ \\
\hline 06 & 58 & $\mathrm{~F}$ & $\mathrm{BM} / \mathrm{MS} / \mathrm{Si}$ & $\mathrm{n} / \mathrm{y}$ & 25 & 4 & 0 & 800 & $\mathrm{R}$ & $\mathrm{n}$ \\
\hline 07 & 71 & M & $\mathrm{MS} / \mathrm{BM} / \mathrm{Si}$ & $\mathrm{n} / \mathrm{y}$ & 143 & 18 & 7 & 987 & $\mathrm{R}$ & $\mathrm{y}$ \\
\hline 08 & 65 & $\mathrm{~F}$ & $\mathrm{MS} / \mathrm{Si} / \mathrm{BM}$ & $\mathrm{n} / \mathrm{y}$ & 29 & 9 & 12 & 950 & $\mathrm{~L}$ & $\mathrm{n}$ \\
\hline 09 & 72 & M & $\mathrm{BM} / \mathrm{MS} / \mathrm{Si}$ & $\mathrm{n} / \mathrm{y}$ & 28 & 14 & 28 & 755 & $\mathrm{R}$ & $\mathrm{n}$ \\
\hline 10 & 65 & $\mathrm{~F}$ & $\mathrm{BM} / \mathrm{Si} / \mathrm{MS}$ & $\mathrm{n} / \mathrm{y}$ & 26 & 11 & 9 & 705 & $\mathrm{R}$ & $\mathrm{n}$ \\
\hline 11 & 65 & M & $\mathrm{MS} / \mathrm{BM} / \mathrm{Si}$ & $\mathrm{n} / \mathrm{y}$ & 27 & 8 & 2 & 895 & $\mathrm{~L}$ & $\mathrm{n}$ \\
\hline 12 & 54 & M & $\mathrm{MS} / \mathrm{Si} / \mathrm{BM}$ & $\mathrm{n} / \mathrm{y}$ & 28 & 7 & 4 & 1485 & $\mathrm{~L}$ & $\mathrm{n}$ \\
\hline $\begin{array}{c}\text { Mean } \pm \\
\text { SD }\end{array}$ & $\begin{array}{l}60.9 \pm \\
8.03\end{array}$ & & & & & $8.83 \pm 4.32$ & $8.5 \pm 7.23$ & & & \\
\hline \multicolumn{11}{|c|}{ Control participants } \\
\hline 01 & 60 & $\mathrm{~F}$ & $\mathrm{BM} / \mathrm{Si} / \mathrm{MS}$ & $\mathrm{n} / \mathrm{y}$ & & & & & & \\
\hline 02 & 61 & M & $\mathrm{MS} / \mathrm{BM} / \mathrm{Si}$ & $\mathrm{y} / \mathrm{y}$ & & & & & & \\
\hline 03 & 62 & M & $\mathrm{BM} / \mathrm{MS} / \mathrm{Si}$ & $\mathrm{n} / \mathrm{y}$ & & & & & & \\
\hline 04 & 56 & M & $\mathrm{MS} / \mathrm{Si} / \mathrm{BM}$ & $\mathrm{y} / \mathrm{y}$ & & & & & & \\
\hline 05 & 50 & M & Si/MS/BM & $\mathrm{n} / \mathrm{y}$ & & & & & & \\
\hline 06 & 50 & $\mathrm{~F}$ & $\mathrm{Si} / \mathrm{BM} / \mathrm{MS}$ & $\mathrm{n} / \mathrm{y}$ & & & & & & \\
\hline 07 & 53 & M & $\mathrm{BM} / \mathrm{Si} / \mathrm{MS}$ & $\mathrm{y} / \mathrm{y}$ & & & & & & \\
\hline 08 & 69 & $\mathrm{~F}$ & $\mathrm{MS} / \mathrm{BM} / \mathrm{Si}$ & $\mathrm{y} / \mathrm{y}$ & & & & & & \\
\hline 09 & 77 & M & $\mathrm{BM} / \mathrm{MS} / \mathrm{Si}$ & $\mathrm{y} / \mathrm{y}$ & & & & & & \\
\hline 10 & 58 & M & $\mathrm{MS} / \mathrm{Si} / \mathrm{BM}$ & $\mathrm{y} / \mathrm{y}$ & & & & & & \\
\hline 11 & 63 & $\mathrm{~F}$ & Si/MS/BM & $\mathrm{n} / \mathrm{y}$ & & & & & & \\
\hline 12 & 68 & M & $\mathrm{Si} / \mathrm{BM} / \mathrm{MS}$ & $\mathrm{y} / \mathrm{y}$ & & & & & & \\
\hline $\begin{array}{c}\text { Mean } \pm \\
\text { SD }\end{array}$ & $60.6 \pm 8.05$ & & & & & & & & & \\
\hline
\end{tabular}

BM, background music; DD, disease duration; F, female; LED, levodopa equivalent dose $;{ }^{55} \mathrm{~L}$, left; M, male; MG, micrographia reported by the patient; MS, musical sonification; R, right; Si, silence. The column "Musical environment" summarizes participant answers to the following two questions: "Do you practice music?" and "Do you listen to music at home?"

expertise. Clinical and demographic information of patients are summarized in Table 1. This study was conducted in accordance with the Declaration of Helsinki, ${ }^{54}$ and approved by the local Ethics Committee Review Board (Project ${ }^{\circ}$ 2012-A00460-43, Comité de Protection des Personnes (CPP), SudMéditerranée 1, France). The participants were included after providing written informed consent.

\section{Experimental protocol}

Participants were comfortably seated in front of a table upon which a graphic tablet was placed (Wacom, Intuos3 A4, sampling frequency $200 \mathrm{~Hz}$ ).
They performed several tasks using an ink pen on a sheet of paper (A4 format: $21.0 \times 29.7 \mathrm{~cm}$ ) affixed to the graphic tablet. The general instruction was to copy the predefined templates on the sheet of paper with the dominant hand. The design included one pretest, three training sessions, and three posttests (Fig. 1).

The pre- and posttests were strictly identical and were carried out in silence: participants were asked to draw (once) loops between dotted lines $(1.6 \mathrm{~cm}$ high), to write (four times) the cursive word "cellule" (cell), and to sign (once). For loop production, the dotted lines were present to require the 


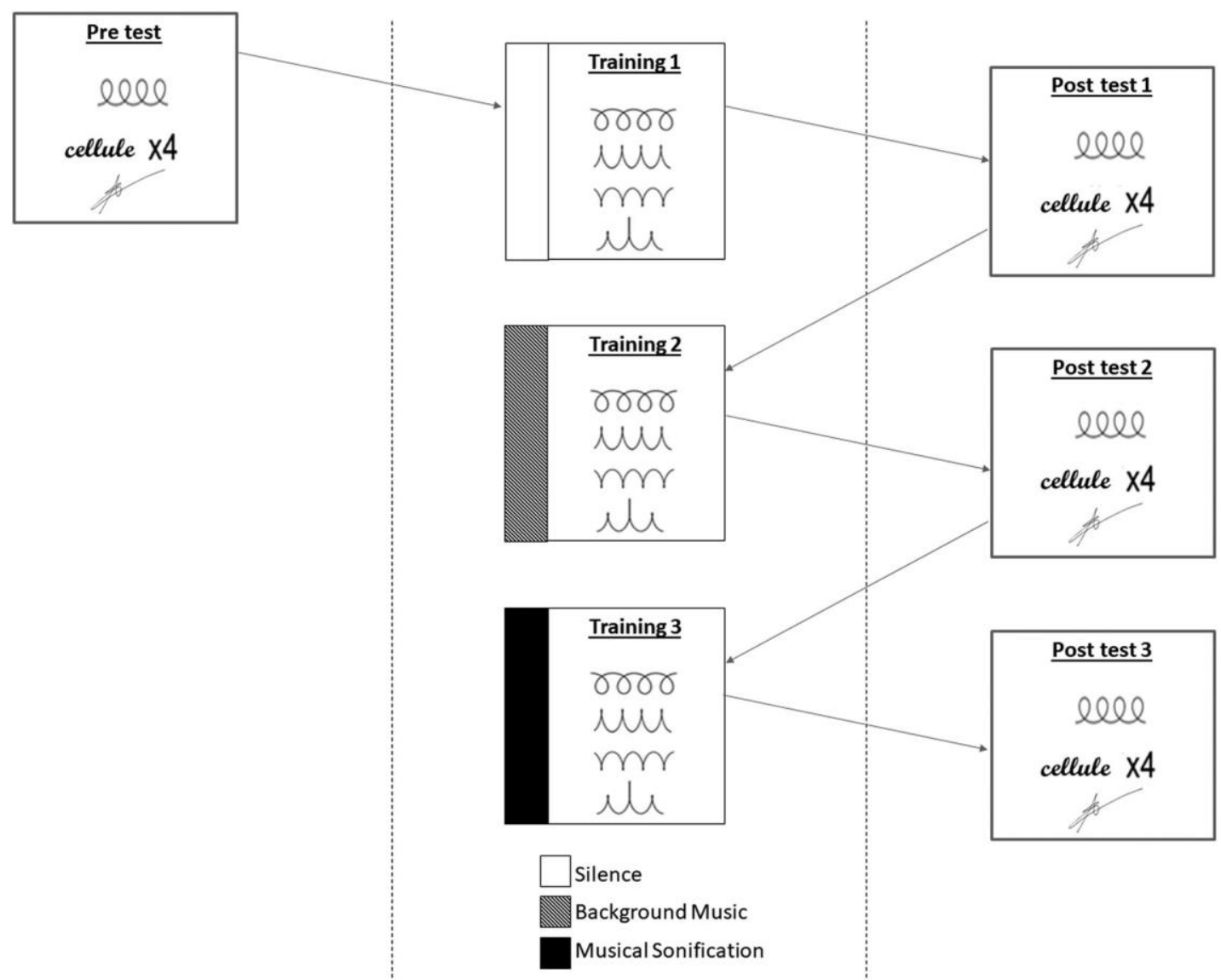

Figure 1. Experimental design of the study. The order of the training conditions was randomized and counterbalanced between participants.

participants to perform larger movements than those they would spontaneously perform. However, when they did not fully follow these lines (if the loops were bigger or smaller), no feedback was given to participants by the experimenter. For the word "cellule," a template was present to avoid any orthographic difficulties: the participants were instructed to write the word with their usual writing. Four segments (5-cm long) were present to indicate where the participants should write. During training sessions, participants were required to practice different graphomotor exercises between dotted lines of 0.8 or $1.6 \mathrm{~cm}$ (for more details, see Supplementary Material S2, online only). As for the tests, no feedback was given to participants when they did not follow the lines.

The training sessions were performed under three experimental conditions: silence (Si), back- ground music, or MS. The order of the training sessions was counterbalanced between participants. A Colombian-type folkloric song (i.e., cumbia) was chosen for both background music and MS training and presented using headphones (Bose SoundLink II). Data recording and MS were controlled by adapting a Max software (http://cycling74.com). In MS, the movement controlled in real-time the music to inform the participants about their drawing/handwriting (for a video example, see Supplementary Material S1, online only). The instantaneous tangential velocity was sonified by the music, with a threshold of $1.5 \mathrm{~cm} \mathrm{~s}^{-1}$ : under this speed, music was distorted; otherwise, it was melodious when movements went past this threshold. The instantaneous pen vertical pressure was associated, in a nonlinear way, to the sound volume: when the pen was in contact with the tablet, the 
music was triggered, and during pen lifts, no music was emitted. ${ }^{56}$ During training with background music or MS, participants were asked to realize their movement with respect to the musical tempo (84 BPM, i.e., 1.4 Hz). During MS, participants were asked to draw without distorting music. The total duration of the experiment was about $30 \mathrm{~min}$, with approximatively 7-min training in each condition.

\section{Data analysis}

Three variables were considered for evaluating the clinical signs of movement disorders related to PD and contributing to Parkinsonian dysgraphia: (1) the mean velocity $(\mathrm{mm} / \mathrm{s})$ for bradykinesia; (2) the mean writing height $(\mathrm{mm})$ for hypokinesia (micrographia); and (3) the mean movement dysfluency (the number of abnormal velocity peaks) determined with the signal-to-noise velocity peaks difference (SNvpd) method developed by Danna et al. ${ }^{57}$ for the evaluation of akinesia and/or freezing of the upper limb. A fourth variable, namely, the mean writing frequency $(\mathrm{Hz})$, was used to estimate the ability of patients to integrate the rhythmic inputs conveyed by the music. The less fluid the movement, the greater the number of abnormal velocity peaks and vice versa. For evaluating loops production, a data preprocessing was needed prior to the measure calculation.

During pre- and posttests, loop production was limited to $6 \mathrm{~s}$ (the minimal production duration recorded in our study) and pen lifts were removed (determined by the absence of the axial pressure measured by the tablet). For training sessions, the duration of loop production was extended to 9 seconds. The local extrema in the $Y$-axis were identified with a Matlab function in order to compute the height and period of each loop. After averaging the periods, the mean frequency was computed as the inverse of the mean period. For the cellule items, the height was computed on the basis of the letters $l$ only.

Performance comparison in the pretest. Group differences between PD patients and control participants during the pretest were estimated for each task (loops drawing, word writing, and signature). Nonparametric tests for two independent samples were applied (Mann-Whitney $U$ test).

\section{Performance comparisons in training sessions.}

The analyses focused on performance in the sec- ond loops line (see Supplementary Material S2). Training conditions (silence, background music, and MS) were compared in order to determine the most efficient one. Three nonparametric analyses were performed here: (1) between-group comparisons, (2) between-training session comparisons, and (3) interactions between groups and training sessions (silence versus background music versus MS). The group effect was analyzed by comparing the performances of PD patients and control participants using nonparametric tests for two independent samples (Mann-Whitney $U$ test). When the comparison between PD and control groups was not different, all participants were gathered into a single group for the between-training comparisons. Between-training session comparisons were performed two by two (namely three comparisons), using nonparametric tests for two-related samples (Wilcoxon test). Separate Wilcoxon tests for posthoc comparisons were computed and a sequentially acceptative step-up Bonferroni procedure was used. ${ }^{58,59}$ Finally, interactions were analyzed with the aligned rank transform (ART) nonparametric factorial design, a method developed by Wobbrock and colleagues. ${ }^{60}$

Post-effect of training sessions. The post-effect of each training session was evaluated. We calculated the difference of performance between each posttest (following silence, background music, and MS) and the pretest (before the first training). Then, we applied the same method of analysis as in the second step, namely: (1) between-group comparisons, (2) between-training sessions comparisons, and (3) group by sessions interaction.

\section{Results}

\section{Performance comparison in the pretest}

Results of the first-step analyses are summarized in Table 2. The velocity and frequency of signature were significantly higher for the control group than for PD patients.

\section{Performance comparisons in training sessions}

The full results are reported in Supplementary Materials S3 (between-group comparisons; online only) and S4 (between-training session comparisons; online only). Mann-Whitney $U$ tests did not reveal any group effect for the four dependent variables. Consequently, all participants were gathered 
Table 2. Performance (mean \pm SEM - $(95 \%$ CI $)$ ) of PD patients and control subjects for the three tasks in pretest

\begin{tabular}{llllrr} 
Pretest & Dependent variables & \multicolumn{1}{c}{ PD group } & \multicolumn{1}{c}{ Control group } & $P$ value & Cohen's $d$ \\
\hline Loops & Frequency $(\mathrm{Hz})$ & $0.76 \pm 0.08(0.60-0.92)$ & $1.04 \pm 0.19(0.66-1.42)$ & 0.59 & -0.409 \\
& Velocity $(\mathrm{mm} / \mathrm{s})$ & $28.92 \pm 3.12(22.68-35.16)$ & $36.92 \pm 5.46(26-47.84)$ & 0.478 & -2.075 \\
& Height $(\mathrm{mm})$ & $13.82 \pm 0.24(13.34-14.3)$ & $13.39 \pm 0.39(12.61-14.17)$ & 0.712 & 0.412 \\
& Dysfluency $(\mathrm{SNvpd})$ & $21.75 \pm 1.46(18.83-24.67)$ & $21.17 \pm 2.23(16.71-25.63)$ & 0.671 & 0.229 \\
\multirow{2}{*}{ Word } & Frequency $(\mathrm{Hz})$ & $0.98 \pm 0.09(0.8-1.16)$ & $1.22 \pm 0.11(1-1.44)$ & 0.143 & -0.408 \\
& Velocity $(\mathrm{mm} / \mathrm{s})$ & $36.2 \pm 3.29(29.62-42.78)$ & $42.2 \pm 3.87(34.46-49.94)$ & 0.478 & -1.704 \\
& Height $(\mathrm{mm})$ & $9.99 \pm 0.53(8.93-11.05)$ & $9.53 \pm 0.59(8.35-10.71)$ & 0.514 & 0.33 \\
& Dysfluency $(\mathrm{SNvpd})$ & $12.77 \pm 3.06(6.65-18.89)$ & $8.94 \pm 1.47(6-11.88)$ & 0.16 & 1.367 \\
\multirow{2}{*}{ Signature } & Frequency $(\mathbf{H z})$ & $\mathbf{3 . 5 4} \pm \mathbf{0 . 2}(\mathbf{3 . 1 4}-\mathbf{3 . 9 4})$ & $\mathbf{4 . 4 3} \pm \mathbf{0 . 2 5}(\mathbf{3 . 9 3}-\mathbf{4 . 9 3})$ & $\mathbf{0 . 0 1 2}$ & $\mathbf{- 1 . 0 0 9}$ \\
& Velocity $(\mathbf{m m} / \mathbf{s})$ & $\mathbf{1 2 3 . 8 6} \pm \mathbf{1 2 . 4 2}(\mathbf{9 9 . 0 2}-\mathbf{1 4 8 . 7})$ & $\mathbf{2 0 2 . 3} \pm \mathbf{2 7 . 6 2}(\mathbf{1 4 7 . 0 6}-\mathbf{2 5 7 . 5 4})$ & $\mathbf{0 . 0 2 8}$ & $\mathbf{- 9 . 4 1 9}$ \\
& Height $(\mathrm{mm})$ & $15.34 \pm 1.21(12.92-17.76)$ & $17.43 \pm 1.99(13.45-21.41)$ & 0.44 & $\mathbf{- 0 . 8 8 8}$ \\
& Dysfluency $(\mathrm{SNvpd})$ & $5.75 \pm 0.79(4.17-7.33)$ & $3.92 \pm 0.74(2.44-5.4)$ & 0.113 & 1.124 \\
\hline
\end{tabular}

Note: Significant differences are in bold.

into a single group for the between-training comparisons (Wilcoxon tests). Significant results are summarized in Figure 2.

Writing frequency was higher during training with background music ( $\pi$ 24, $Z=2.06, P=0.04$ ) and training with MS ( $F 24, Z=2.6, P=0.009$ ) than during training in silence (Fig. 2A). Concerning writing velocity, Wilcoxon tests showed that loops were produced faster during training with MS than during training in silence $(n=24$, $Z \neq .00, P$ 0:04; Fig. 2B). No significant effect was observed for writing height and dysfluency. Finally, no interactions between groups and sessions were observed.

\section{Post-effect of training sessions}

The full results are reported in Supplementary Materials S3 (between-group comparisons) and S4 (between-training session comparisons). Significant results are summarized in Figures 3 and 4.

Loops. Mann-Whitney $U$ test revealed that Parkinsonian participants increased their writing tempo more than control participants after training under MS ( $n=12, U=2.34, P=0.017$; Fig. $3 \mathrm{~A}$ ). Wilcoxon tests revealed significant differences for movement frequency for the Parkinsonian group only. PD participants increased their writing tempo more after training under MS than after training in silent $(n=12, Z=2.04, P=0.04)$ and with background music $(n=12, Z=2.27, P=0.023$; Fig. 3A). The group by session interaction did not reach the significance threshold for frequency by the ART analysis $(F(2,44)=2.41, P=0.10)$.
Mann -Whitney $U$ test revealed that Parkinsonian participants increased their writing velocity more than control participants after training under MS ( $n \neq 2, U 2.05, P 0.039$; Fig. 3B). Wilcoxon

tests revealed that both PD patients $(n=12$, $Z \approx .75, P<0.01$; Fig. 3B) and control participants ( $n=2, Z \neq 04, P$ F.04; Fig. 3B) increased their velocity more after training under MS than after training with background music. Again, the interaction did not reach the significance threshold for mean velocity $(F(2,4) 2.66, P=0.08)$. No significant effect or interaction was observed for writing height and dysfluency.

Word. Mann Whitney $U$ test did not show any difference between participant groups. Wilcoxon tests revealed that the pre/post difference of velocity was higher after training with MS than after training with background music $(n=24, Z=2.46$, $P$ Ө.014; Fig. 4A). Mann Whitney $U$ test revealed that letters height of Parkinsonian participants increased more than control participants after training under MS $(n=12, U=-2.05$, $P$ Ð.039). Wilcoxon tests revealed that dysfluency decreased more after training with MS than after training under silence $(n=22, Z=2.04$, $P=0.04)$ and background music $(n=22, Z=2.04$, $P=0.027$; Fig. 4B). No other significant effect was observed for the writing frequency. Finally, no interactions between group and session factors were observed.

Signature. Mann Whitney $U$ test revealed that Parkinsonian participants increased their signature 
A

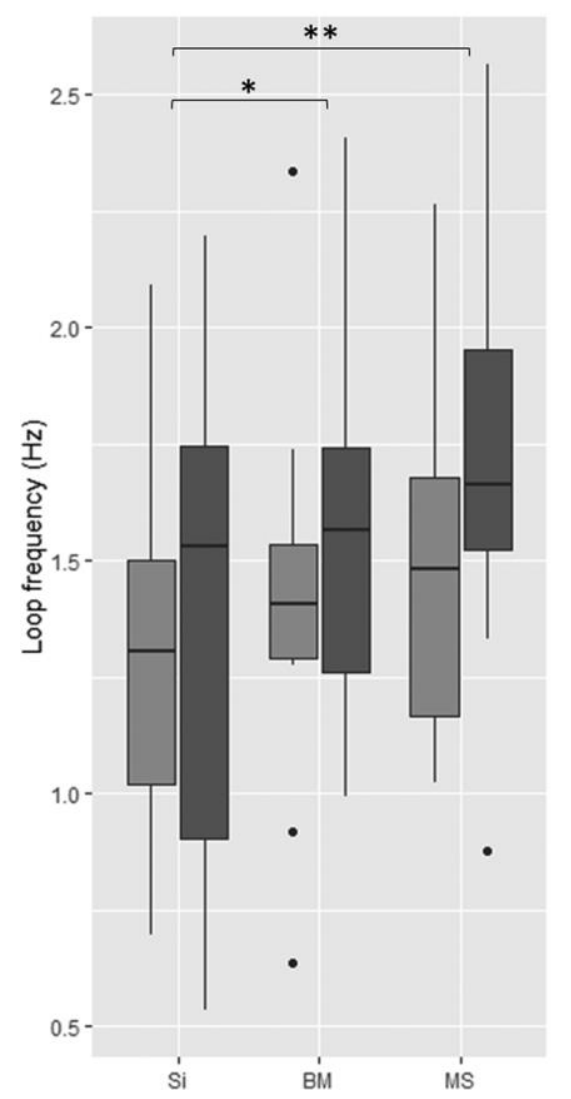

B

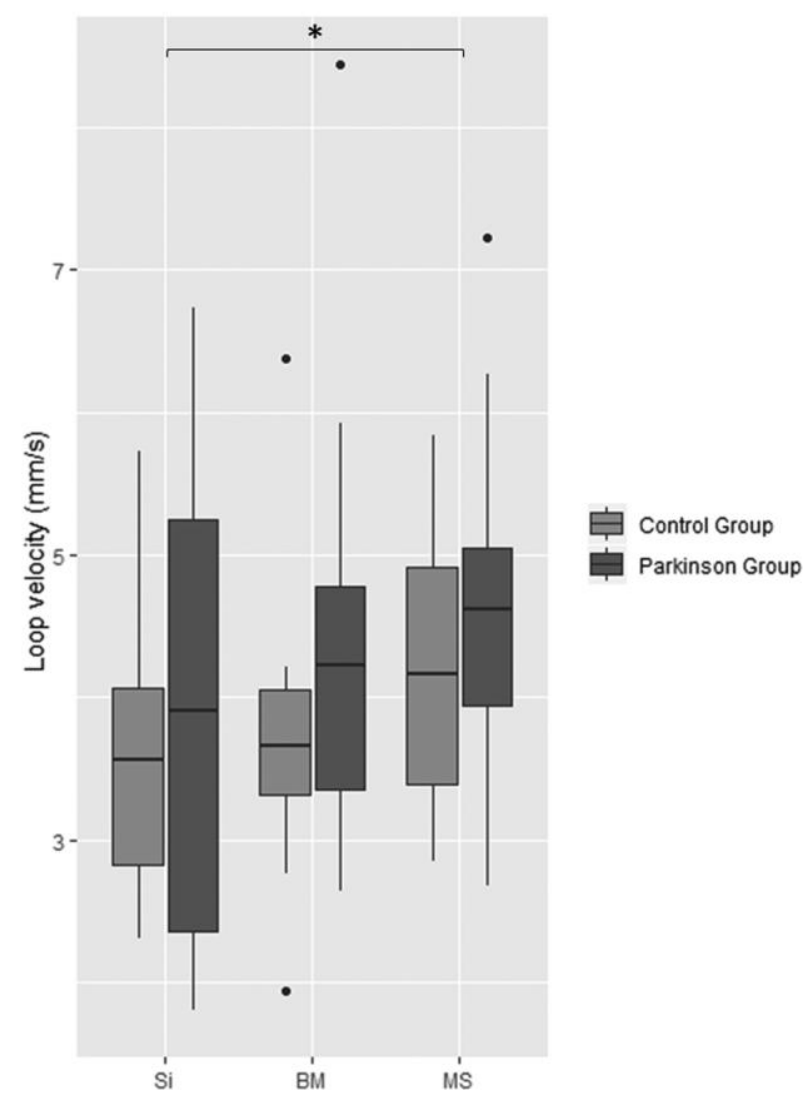

Figure 2. Movement frequency (A) and velocity (B) of the loop production task during the training, for both control and Parkinsonian groups. ${ }^{*} P<0.05 ;{ }^{* *} P<0.01{ }^{* * *} P<0.001$. Si, silence; $\mathrm{BM}$, background music; MS, musical sonification.

tempo more than control participants after training in silence ( $\neq 12, \notin z .05, P \neq 0.039)$. Statistical analyses did not show any other group or condition effectforfrequency, velocity, height, and dysfluency, and any interactions between group and session factors.

\section{Discussion}

In this study, we evaluated the relevance of MS as a potential tool for managing handwriting impairments in patients with PD. To this aim, we investigated changes associated with PD on different writing movements, ranging from less (loops) to more (signature) automatized, before and after training under silence, background music, and MS. We observed that prior to the training, both control and patient groups performed similarly, except for the signature that was slower for the PD patients. Dur- ing training, movement frequency increased both under background music and MS. Interestingly, movement velocity was improved only under MS. The increase in frequency and velocity was maintained after training with MS more significantly for the Parkinsonian group than for the control group. Below, these results are discussed according to the experimental design.

\section{Pretest state}

At baseline, prior to any training, the performance of patients with PD did not differ from that of control participants, except for the signature. It has been demonstrated that visual cueing provides immediate beneficial effects in handwriting. ${ }^{39,40,43}$ In our tasks, only the signature was performed without the presence of dotted lines or a template, avoiding the PD group to use the adaptation 
A

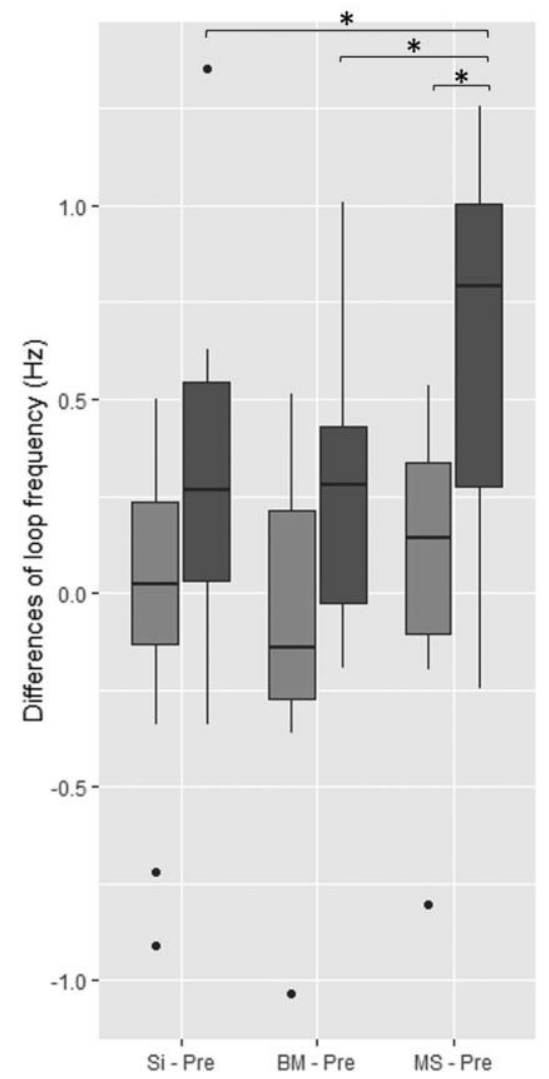

B

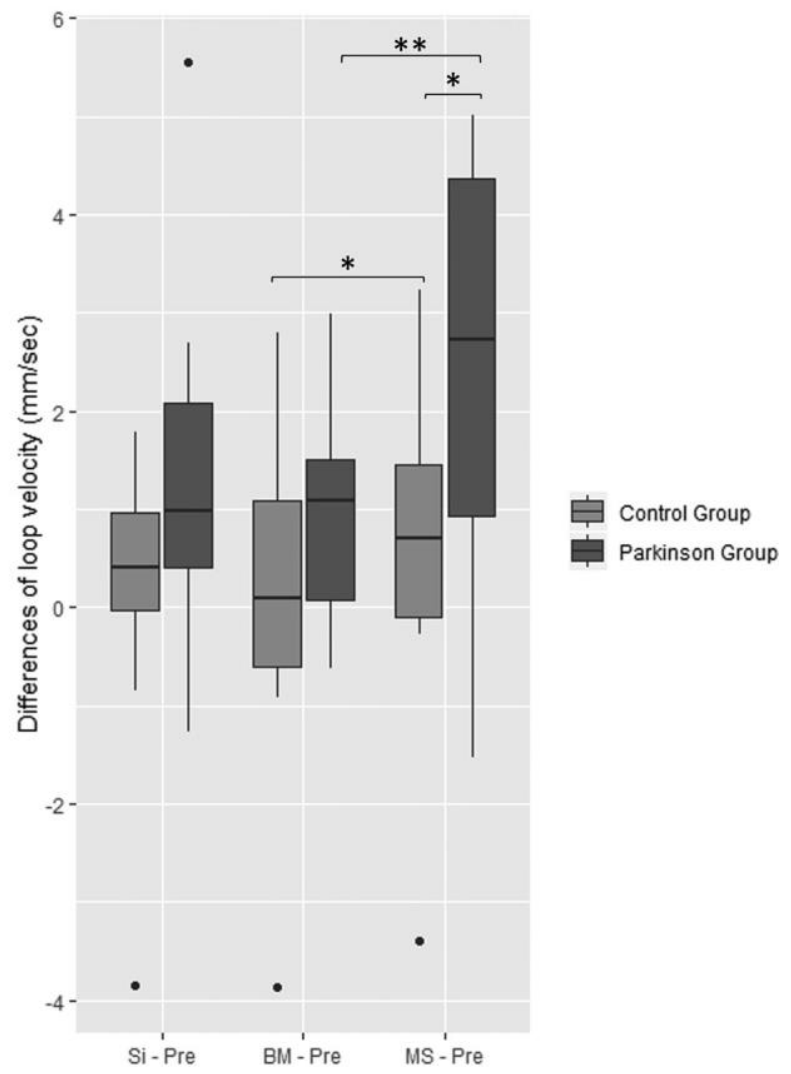

Figure 3. Pre-/posttraining differences of the frequency $(A)$ and the velocity $(B)$ of the loop production, for both control and Parkinsoniangroups. ${ }^{*} P<0.05 ;{ }^{* *} P<0.01 ;{ }^{* * *} P<0.001$. Si, silence; BM, background music; MS, musical sonification.

strategy based on external visual constraints. Furthermore, it should be noted that patients were under medication when performing the tasks. Medical treatment restores, at least partially, writing movements. ${ }^{11,35,36,61,62}$ Motor-based rehabilitation programs, such as the one we aimed at evaluating in this study, are generally addressed to patients administered optimal medication by the therapist, in order to combine positive effects of both treatments. From this perspective, MS is considered here as a complementary strategy to medication, and thus, being under medical treatment inscribes our experimentation in a functional, ecological context. However, although PD patients were on medication, their signature remained slower than control participants. This finding supports two complementary hypotheses. First, automatized movements are mostly affected by $\mathrm{PD}^{36,63}$ and we can reasonably infer that the PD signs, partially restored by medication, still have an impact on the performance for the most automated movements, such as the signature. Second, our results revealed that the differences in mean velocity between PD and control groups were lower for words (14\%) than for signatures (39\%). Because the signature is the most rapid movement of handwriting, it is likely more vulnerable to bradykinesia. ${ }^{64,65}$ Such impairments might not be exclusively assignable to the inability of producing a movement with a particular size and speed: decreasing size and/or speed could also reflect an adaptive strategy used to improve movement control ${ }^{66}$ and to sign ina more comfortable way to face the evolution of the disease. In handwriting, movement frequency results from a compromise between movement velocity and amplitude. The size of the signature is maintained, but the velocity is slowed down, which directly decreases the movement frequency. 
A

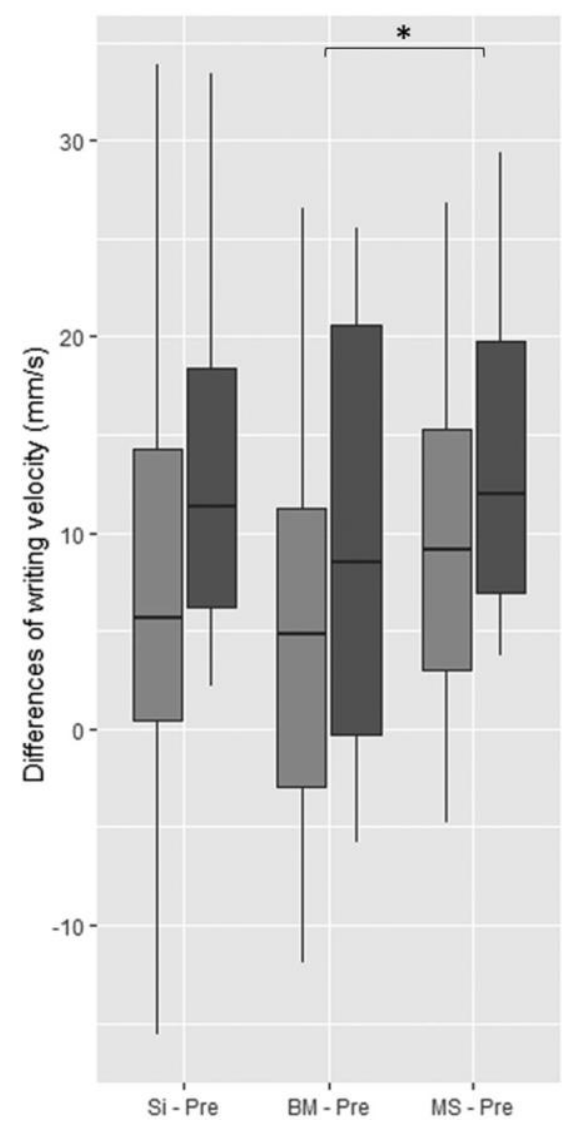

B

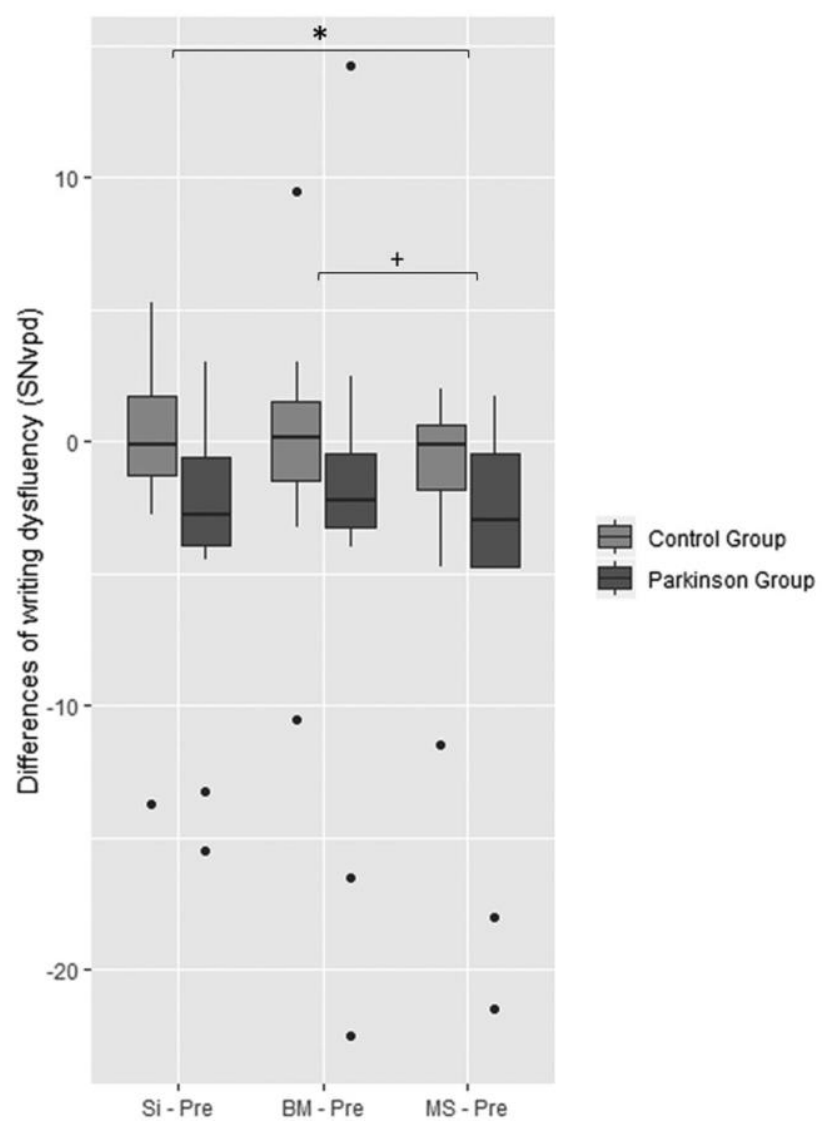

Figure 4. Pre-/posttraining differences of the velocity (A) and the dysfluency (B)for the word writing, inboth controland Parkinsonian groups. ${ }^{*} P<0.05$; ${ }^{* *} P<0.01 ;{ }^{* * *} P<0.001$. Si, silence; $\mathrm{BM}$, background music; MS, musical sonification.

\section{Effects of training sessions}

During training, again no group effects were revealed, probably due to the effects of medical treatment in the PD group or due to the presence of the dotted lines used by the PD patients as visual cues. According to our predictions, both background music and MS increased movement frequency, but not silence. Such increases in frequency were most likely related to the natural, spontaneous, and universal tendency to synchronize movements with music. ${ }^{7,67,68}$ Several studies, developed on this assumption, demonstrated that rhythmic or musical auditory cueing was able to catalyze the effects of motor rehabilitation protocols in PD patients and to induce an improvement of performance in healthy subjects. ${ }^{9-11,69}$ Our results corroborate these studies and suggest that auditory cueing seems efficient either in background music or using MS. Furthermore, we observed a specific effect of MS on loop velocity. Under MS, participants were constrained to reach a minimum threshold of velocity to avoid distorting music. Participants were doubly constrained in MS: they had to increase both writing frequency (to synchronize their movement) and velocity (to avoid music distortions). The explicit feedback on the velocity compels the participants to focus on this parameter. Directing attention specifically to movements can be facilitatory, possibly because it reduces the automaticity of actions, which is impaired in $\mathrm{PD},{ }^{9,70}$ and gives a clear and precise objective to achieve. ${ }^{38,39}$

\section{Post-effect changes}

Globally, post-effects of training were modest, probably because of the very short training duration in each condition ( 7 minutes). The specific effect of 
MS on movement velocity and frequency was maintained in the loop production during the posttest and remarkably, such effects were greater for PD patients than for control participants. We also observed a transfer effect to the velocity of word writing, a task that was not trained and was more automatized compared with the loop production. Interestingly, the increase in word writing velocity after training under MS went along with an increase in word writing height in PD patients. Unlike loops, words did not have to be written between two lines, so the height of the letters was no longer constrained allowing the participant to increase it as needed. The relationship between handwriting velocity and amplitude has been precisely investigated in PD patients and external cueing has been shown to help patients to overcome deficits in speed or amplitude scaling. ${ }^{64}$ Furthermore, our results show that the increase in writing velocity was accompanied by an improvement in the fluency of movement: the number of abnormal velocity peaks decreased. Our results are in agreement with those of Chartrel and Vinter, ${ }^{71}$ who compared the effects of spatial and temporal constraints on children's writing and demonstrated that the addition of temporal constraints was able to improve both the speed and fluidity of writing movement. Finally, the difference in intergroup performance, highlighted in the pretest, disappeared at the posttest: PD patients no longer signed slower than control participants, even with a difference of frequency that becomes more significant at the end of the silent training sessions. These results were mainly related to the overall effect of training, supporting the assumption that PD patients can relearn but with slower learning rates than controls. ${ }^{10,12}$

The beneficial effect of MS can be discussed at sensorimotor, attentional, and motivational levels. At a sensorimotor level, the transfer of MS to the performance in the silent posttest may be discussed in light of the Event Coding Theory, ${ }^{72,73}$ which considers cognitive representations as a structural coupling between perception and action. In this view, the visual and proprioceptive signals accompanying the movement of the pen would be associated with music and integrated to provide a multisensory representation. In the posttest, in silence, this representation was also reactivated. Among others, this hypothesis is supported by Bangert and colleagues, ${ }^{74}$ who demon- strated that executing silent finger movements on a piano keyboard elicited stronger activation of auditory-sensory areas after a piano training. In the case of handwriting, the positive transfer effect was also observed after learning to write new characters with sonification. ${ }^{75}$ At an attentional level, music distortions increased the participants online control, informing them in real time, and explicitly, about their performance during training. For the management of PD disorders, it seems that the techniques directing the attention toward a single parameter, for example, speech loudness for the LSVT-LOUD( ${ }^{76,77}$ or letter amplitude with visual cueing, ${ }^{38,39,43,78}$ are very efficient. Furthermore, these studies have highlighted the long-term post-effect of such method. ${ }^{77}$ At an emotional level, it should be noted that the emotional state of music differs between the background music and MS conditions: music also becomes a reward in sonification, since it informs on the correctness of the movement. This supplementary status of music involves a supplementary neural network, the mesolimbic pathway, which contributes to the reinforcement and reward-related motor function learning, as well as in the subjective perception of pleasure. ${ }^{79-82}$ This is of particular importance for PD patients for whom the reward pathway is impacted. ${ }^{83-85}$

\section{Conclusion and perspectives}

Our study established a proof of concept highlighting the specific effect of MS on the motor control of handwriting. The interest of this study goes beyond the rehabilitation of Parkinsonian dysgraphia: it provides new arguments to use MS as an original, simple, and easy to reach auditory guidance strategy for movement rehabilitation in PD patients. From a neural perspective, many theoretical arguments support MS for rehabilitation protocols in PD patients. First, Schmitz and colleagues ${ }^{86}$ showed that the observation of sonified movements by healthy subjects activates the striato thalamo eortical (STC) circuitry. Therefore, one can wonder whether applying such a realtime supplementary auditory feedback could be relevant for enhancing the STC network that is disrupted in PD patients. Second, while rhythmic component of musical sounds involves the recruitment of the cerebelle thalamo-cortical pathway, one can also wonder whether this might be a possible strategy to overcome the deficit of the 
activation of the STC circuitry in PD. ${ }^{9}$ Finally, beyond movement, MS would also stimulate the reward network impacted by PD. Further studies will have to investigate the effects of MS in an intensive and long-term management protocol, and concomitantly, to study the neuroanatomical underpinnings of the associated functional reorganization.

\section{Acknowledgments}

We wish to thank Alia Afyouni, Cyril AtkinsonClément, Florent Boullé, and Marie-Charlotte Cuartero for their helpful contributions to this work. This research was supported by the French Research and Education Ministry (PhD grant scheme), ANR-16-CONV-0002 (ILCB), ANR-11LABX0036 (BLRI), and ANR-11-IDEX-0001-02 (A*MIDEX). It was also supported by a grant from the "Association France Parkinson."

\section{Author contributions}

L.V.D., S.P., and J.D. contributed to the design of the experiment. L.V.D., J.D., A.E., J.P.A., and T.W. conducted the experiments. L.V.D., S.P., and J.D. analyzed the results. All authors contributed to the writing of the manuscript and approved the final version.

\section{Supporting information}

Additional supporting information may be found in the online version of this article.

\section{Supplementary Material S1. Video.}

Supplementary MaterialS2. Illustration of training stimuli.

Supplementary Material S3. Performance (mean \pm SEM) during the training sessions ( $\mathrm{Si}$, silence; $\mathrm{BM}$, background music; MS, musical sonification) and performance differences between the posttest and pretest (mean \pm SEM) of PD patients and control subjects for each task. Significant differences are in bold.

Supplementary Material S4. Performance (mean \pm SEM) during the training sessions ( $\mathrm{Si}$, silence; $\mathrm{BM}$, background music; MS, musical sonification) and performance differences between the posttest and pretest (mean \pm SEM) of all participants (gathered into a single group) for each task.

\section{Competing interests}

The authors declare no competing interests.

\section{References}

1. Dalla Bella, S. 2018. Music and movement: towards a translational approach. Neurophysiol. Clin. 48: 377-386.

2. Van Vugt, F.T., J. Ritter, J.D. Rollnik \& E. Altenmüller. 2014. Music-supported motor training after stroke reveals no superiority of synchronization in group therapy. Front. Hum. Neurosci. 8: 315.

3. Forsblom, A., S. Laitinen, T. Särkämö \& M. Tervaniemi. 2009. Therapeutic role of music listening in stroke rehabilitation. Ann. N.Y. Acad. Sci. 1169:426-430.

4. Chen, J.L., R.J. Zatorre \& V.B. Penhune. 2006. Interactions between auditory and dorsal premotor cortex during synchronization to musical rhythms. Neuroimage 32: 17711781.

5. Thaut, M.H., G.C. McIntosh, R.R. Rice, et al. 1996. Rhythmic auditory stimulation in gait training for Parkinson's disease patients. Mov. Disord. 11: 193-200.

6. McIntosh, G.C., S.H. Brown, R.R. Rice \& M.H. Thaut. 1997. Rhythmic auditory-motor facilitation of gait patterns in patients with Parkinson's disease. J. Neurol. Neurosurg. Psychiatry 62: 22-26.

7. Zatorre, R.J., J.L. Chen \& V.B. Penhune. 2007. When the brain plays music: auditory-motor interactions in music perception and production. Nat. Rev. Neurosci. 8: 547-558.

8. Mainka, S. 2015. Music stimulates muscles, mind, and feelings in one go. Front. Psychol. 6: 1547.

9. Nombela, C., L.E. Hughes, A.M. Owen \& J.A. Grahn. 2013. Into the groove: can rhythm influence Parkinson's disease? Neurosci. Biobehav. Rev. 37:2564-2570.

10. Nieuwboer, A., L. Rochester, L. Müncks \& S.P. Swinnen. 2009. Motor learning in Parkinson's disease: limitations and potential for rehabilitation. Parkinsonism Relat. Disord. 15: S53-S58.

11. Véron-Delor, L., S. Pinto \& A. Eusebio, et al. 2018. Music and musical sonification for the rehabilitation of Parkinsonian dysgraphia: conceptual framework. In Music Technology with Swing. M. Aramaki, M.E.P. Davies, R. KronlandMartinet \& S. Ystad, Eds.: 312-326. Springer International Publishing.

12. Dalla Bella, S., C.-E. Benoit, N. Farrugia, et al. 2017. Gait improvement via rhythmic stimulation in Parkinson's disease is linked to rhythmic skills. Sci. Rep. 7: 42005.

13. Ledger, S., R. Galvin, D. Lynch \& E.K. Stokes. 2008. A randomised controlled trial evaluating the effect of an individual auditory cueing device on freezing and gait speed in people with Parkinson's disease. BMC Neurol. 8. https://doi.org/ 10.1186/1471-2377-8-46.

14. Young, W.R., L. Shreve, E.J. Quinn, et al. 2016. Auditory cueing in Parkinson's patients with freezing of gait. What matters most: action-relevance or cue-continuity? Neuropsychologia 87: 54-62.

15. Pilon, M.A., K.W. McIntosh \& M.H. Thaut. 1998. Auditory vs visual speech timing cues as external rate control to enhance verbal intelligibility in mixed spastic-ataxic dysarthric speakers: a pilot study. Brain Inj. 12: 793-803. 
16. Brendel,B.\&W.Ziegler. 2008. Effectiveness of metrical pacing in the treatment of apraxia of speech. Aphasiology 22: 77-102.

17. Toyomura, A., T. Fujii \& S. Kuriki. 2011. Effect of external auditory pacing on the neural activity of stuttering speakers. Neuroimage 57: 1507-1516.

18. Fujii, S. \& C.Y. Wan. 2014. The role of rhythm in speech and language rehabilitation: the SEP hypothesis. Front. Hum. Neurosci. 8. https://doi.org/10.3389/fnhum.2014.00777.

19. Delval, A., L. Defebvre \& C. Tard. 2017. Freezing during tapping tasks in patients with advanced Parkinson's disease and freezing of gait. PLoS One 12: $\mathrm{e} 0181973$.

20. Nieuwboer, A., S. Vercruysse, P. Feys, et al. 2009. Upper limb movement interruptions are correlated to freezing of gait in Parkinson's disease. Eur. J. Neurosci. 29: 14221430 .

21. Debaere, F., N. Wenderoth, S. Sunaert, et al. 2003. Internal vs external generation of movements: differential neural pathways involved in bimanual coordination performed in the presence or absence of augmented visual feedback. Neuroimage 19: 764-776.

22. Jahanshahi, M., J.H. Jenkins, R.G. Brown, et al. 1995. Selfinitiated versus externally triggered movements. I. An investigation using measurement of regional cerebral blood flow with PET and movement-related potentials in normal and Parkinson's disease subjects. Brain J. Neurol. 118(Pt 4): 913-933.

23. Jenkins, I.H., M. Jahanshahi, M. Jueptner, et al. 2000. Selfinitiated versus externally triggered movements. II. The effect of movement predictability on regional cerebral blood flow. Brain J. Neurol. 123(Pt 6): 1216-1228.

24. Doyon, J. \& H. Benali. 2005. Reorganization and plasticity in the adult brain during learning of motor skills. Curr. Opin. Neurobiol. 15: 161-167.

25. Mentis, M.J., V.Dhawan, T. Nakamura, et al. 2003. Enhancement of brain activation during trial-and-error sequence learning in early PD. Neurology 60: 612-619.

26. Cochen De Cock, V., D.G. Dotov, P. Ihalainen, et al. 2018. Rhythmic abilities and musical training in Parkinson's disease: do they help? Npj Park. Dis. 4: 1-8.

27. Rodger, M.W.M. \& C.M. Craig. 2016. Beyond the metronome: auditory events and music may afford more than just interval durations as gait cues in Parkinson's disease. Front. Neurosci. 10:272.

28. Margolin, D.I. \& A.M. Wing. 1983. Agraphia and micrographia: clinical manifestations of motor programming and performance disorders. Acta Psychol. (Amst.) 54: 263283.

29. Lewitt, P.A. 1983. Micrographia as a focal sign of neurological disease. J. Neurol. Neurosurg. Psychiatry 46: 1152.

30. Phillips, J.G., G.E. Stelmach \& N. Teasdale. 1991. What can indices of handwriting quality tell us about Parkinsonian handwriting? Hum. Mov. Sci. 10:301-314.

31. Gross, L.J. 1975. Drug-induced handwriting changes: an empirical review. Tex. Rep. Biol. Med. 33: 370-390.

32. Blank, R., V.Miller, H. von Voss \& R. von Kries. 1999. Effects of age on distally and proximally generated drawing movements: a kinematic analysis of school children and adults. Dev. Med. Child Neurol. 41:592-596.
33. Letanneux, A., J. Danna, J.-L. Velay, et al. 2014. From micrographia to Parkinson's disease dysgraphia: Parkinson's disease dysgraphia. Mov. Disord. 29: 1467-1475.

34. Pinto, S. \& J.-L. Velay. 2015. Handwriting as a marker for PD progression: a shift in paradigm. Neurodegener. Dis. Manag. 5: 367-369.

35. Lange, K.W., K. Mecklinger, S. Walitza, et al. 2006. Brain dopamine and kinematics of graphomotor functions. Hum. Mov. Sci. 25: 492-509.

36. Tucha, O., K. Mecklinger, J. Thome, et al. 2006. Kinematic analysis of dopaminergic effects on skilled handwriting movements in Parkinson's disease. J. Neural Transm. 113: 609-623.

37. McLennan, J.E., L. Nakano, H.R. Tyler\& R.S. Schwab. 1972. Micrographia in Parkinson's disease. J. Neurol. Sci. 15: 141152.

38. Ringenbach, S.D.R.,A.W.A.van Gemmert,H.A.Shill\& G.E. Stelmach. 2011. Auditory instructional cues benefit unimanual and bimanual drawing in Parkinson's disease patients. Hum. Mov. Sci. 30: 770-782.

39. Oliveira, R.M., J.M. Gurd, P.Nixon, et al. 1997. Micrographia in Parkinson's disease: the effect of providing external cues. J. Neurol. Neurosurg. Psychiatry 63: 429-433.

40. Bryant, M., D. Rintala, E. Lai \& E. Protas. 2010. An investigation of two interventions for micrographia in individuals with Parkinson's disease. Clin. Rehabil. 24: 10211026.

41. Contreras-Vidal, J.L., H.-L. Teulings, G.E. Stelmach \& C.H. Adler. 2002. Adaptation to changes in vertical display gain during handwriting in Parkinson's disease patients, elderly and young controls. Parkinsonism Relat. Disord. 9: 77-84.

42. Teulings, H.L., J.L. Contreras-Vidal, G.E. Stelmach \& C.H. Adler. 2002. Adaptation of handwriting size under distorted visual feedback in patients with Parkinson's disease and elderly and young controls. J. Neurol. Neurosurg. Psychiatry 72: 315-324.

43. Nackaerts, E., A. Nieuwboer, S. Broeder, et al. 2016. Opposite effects of visual cueing during writing-like movements of different amplitudes in Parkinson's disease. Neurorehabil. Neural Repair 30: 431-439.

44. Danna, J. \& J.-L. Velay. 2017. Handwriting movement sonification: why and how? IEEE Trans. Hum. Mach. Syst. 47: 299-303.

45. Kramer, G. 1994. Auditory Display: Sonification, Audification, and Auditory Interfaces. (Santa Fe Institute Studies in the Sciences of Complexity Proceedings). Vol. XVIII. Reading, MA: Addison-Wesley.

46. Schmitz, G., J. Bergmann, A.O. Effenberg, et al. 2018. Movement sonification in stroke rehabilitation. Front. Neurol. 9. https://doi.org/10.3389/fneur.2018.00389.

47. Danna, J. \& J.-L. Velay. 2017. On the auditory-proprioception substitution hypothesis: movement sonification in two deafferented subjects learning to write new characters. Front. Neurosci. 11: 137.

48. Wittwer, J.E., K.E. Webster \& K. Hill. 2013. Music and metronome cues produce different effects on gait spatiotemporal measures but not gait variability in healthy older adults. Gait Posture 37: 219-222. 
49. Dyer, J.F., P. Stapleton \& M.W. Rodger. 2017. Advantages of melodic over rhythmic movement sonification in bimanual motor skill learning. Exp. Brain Res. 235: 3129-3140.

50. Ackerley, R., J.M. Aimonetti \& E. Ribot-Ciscar. 2017. Emotions alter muscle proprioceptive coding of movements in humans. Sci. Rep. 7: 8465.

51. Nasreddine, Z.S., N.A. Philips, V. Bédirian, et al. 2005. The Montreal Cognitive Assessment, MoCA: a brief screening tool for mild cognitive impairment. J. Am. Geriatr. Soc. 53: 695-699.

52. Mattis, M. 1976. Mental status examination for organic mental syndrome in the elderly patient. In Geriatric Psychiatry. L. Bellack \& T. Karasu, Eds.: 77-121. New York, NY: Grune $\&$ Stratton Inc.

53. Goetz, C.G., B.C. Tilley, S.R. Shaftman, et al. 2008. Movement Disorder Society-sponsored revision of the Unified Parkinson's Disease Rating Scale (MDS-UPDRS): scale presentation and clinimetric testing results. Mov. Disord. 23: 2129-2170.

54. World Medical Association. 2013. Declaration of Helsinki: ethical principles for medical research involving human subjects. JAMA 310: 2191.

55. Tomlinson, C.L., R. Stowe, S. Patel, et al. 2010. Systematic review of levodopa dose equivalency reporting in Parkinson's disease: systematic review of LED reporting in PD. Mov. Disord. 25: 2649-2653.

56. Danna, J., V. Paz-Villagrán \& A. Capel, et al. 2014. Movement sonification for the diagnosis and the rehabilitation of graphomotor disorders. In Sound, Music, and Motion. M. Aramaki, O. Derrien, R. Kronland-Martinet \& S. Ystad, Eds.: 246-255. Springer International Publishing.

57. Danna, J., V. Paz-Villagrán \& J.-L. Velay. 2013. Signal-tonoise velocity peaks difference: a new method for evaluating the handwriting movement fluency in children with dysgraphia. Res. Dev. Disabil. 34: 4375-4384.

58. Hochberg, Y. 1988. A sharper Bonferroni procedure for multiple tests of significance. Biometrika 75: 800-802.

59. Keselman, H.J. 1994. Stepwise and simultaneous multiple comparison procedures of repeated measures' means. J. Educ. Stat. 19: 127.

60. Wobbrock, J.O., L. Findlater, D. Gergle \& J.J. Higgins. 2011. The aligned transform for nonparametric factorial analyses using only ANOVA procedures. In Proceedings of $\mathrm{CHI}^{*} 11$. New York, NY: ACM Press, 143-146.

61. Saunders-Pullman, R., C. Derby, K. Stanley, et al. 2008. Validity of spiral analysis in early Parkinson's disease. Mov. Disord. 23: 531-537.

62. Poluha, P.C., H.L. Teulings \& R.H. Brookshire. 1998. Handwriting and speech changes across the levodopa cycle in Parkinson's disease. Acta Psychol. (Amst.) 100: 71-84.

63. Wagle Shukla, A., S. Ounpraseuth, M.S. Okun, et al. 2012. Micrographia and related deficits in Parkinson's disease: a cross-sectional study. BMJ Open 2: e000628.

64. Teulings, H.-L. \& G.E. Stelmach. 1991. Control of stroke size, peak acceleration, and stroke duration in Parkinsonian handwriting. Hum. Mov. Sci. 10:315-334.

65. Van Gemmert, A.W.A. 2003. Parkinson's disease patients undershoot target size in handwriting and similar tasks. J. Neurol. Neurosurg. Psychiatry 74: 1502-1508.
66. Longstaff, M.G., P.R. Mahant, M.A. Stacy, et al. 2003. Discrete and dynamic scaling of the size of continuous graphic movements of parkinsonian patients and elderly controls. J. Neurol. Neurosurg. Psychiatry 74:299-304.

67. Bangert, M., T. Peschel, G. Schlaug, et al. 2006. Shared networks for auditory and motor processing in professional pianists: evidence from fMRI conjunction. Neuroimage 30: 917-926.

68. Schaefer, R.S. 2014. Auditory rhythmic cueing in movement rehabilitation: findings and possible mechanisms. Philos. Trans. R. Soc. B Biol. Sci. 369: 20130402.

69. Dalla Bella, S., C.-E. Benoit, N. Farrugia, et al. 2015. Effects of musically cued gait training in Parkinson's disease: beyond a motor benefit. Ann. N.Y. Acad. Sci. 1337: 77-85.

70. Morris, M.E., R. Iansek, T.A. Matyas \& J.J. Summers. 1996. Stride length regulation in Parkinson's disease. Normalization strategies and underlying mechanisms. Brain J. Neurol. 119(Pt 2): 551-568.

71. Chartrel, E. \& A. Vinter. 2008. The impact of spatiotemporal constraints on cursive letter handwriting in children. Learn. Instr. 18: 537-547.

72. Hommel, B., J. Müsseler, G. Aschersleben \& W. Prinz. 2001. The Theory of Event Coding (TEC): a framework for perception and action planning. Behav. Brain Sci. 24: 849-878; discussion 878-937.

73. Prinz, W. 1997. Perception and action planning. Eur. J. Cogn. Psychol. 9: 129-154.

74. Bangert, M., U. Haeusler \& E. Altenmüller. 2001. On practice: how the brain connects piano keys and piano sounds. Ann. N.Y. Acad. Sci. 930: 425-428.

75. Danna, J., M. Fontaine, V. Paz-Villagrán, et al. 2015. The effect of real-time auditory feedback on learning new characters. Hum. Mov. Sci. 43: 216-228.

76. Ramig, L.O., S. Countryman, L.L. Thompson \& Y. Horii. 1995. Comparison of two forms of intensive speech treatment for Parkinson disease. J. Speech Hear. Res. 38: 1232 1251 .

77. Atkinson-Clement, C., J. Sadat \& S. Pinto. 2015. Behavioral treatments for speech in Parkinson's disease: meta-analyses and review of the literature. Neurodegener. Dis. Manag. 5: 233-248.

78. Van Gemmert, A.W.A., H.-L. Teulings, J.L. Contreras-Vidal \& G.E. Stelmach. 1999. Parkinsons disease and the control of size and speed in handwriting. Neuropsychologia 37: 685694.

79. Olds, J. \& P. Milner. 1954. Positive reinforcement produced by electrical stimulation of septal area and other regions of rat brain. J. Comp. Physiol. Psychol. 47: 419-427.

80. Schultz, W.2007. Behavioral dopamine signals. Trends Neurosci. 30: 203-210.

81. Leyton, M. 2010. The neurobiology of desire: dopamine and the regulation of mood and motivational states in humans. In Pleasures of the Brain. M.L. Kringelbach \& K.C. Berridge, Eds.: 222-243. New York, NY: Oxford University Press.

82. Glimcher, P.W. 2011. Understanding dopamine and reinforcement learning: the dopamine reward prediction error hypothesis. Proc. Natl. Acad. Sci. USA 108: 1564715654. 
83. Di Chiara, G. 1998. A motivational learning hypothesis of the role of mesolimbic dopamine in compulsive drug use. J. Psychopharmacol. (Oxf.) 12:54-67.

84. Bressan, R.A. \& J.A. Crippa. 2005. The role of dopamine in reward and pleasure behavior - review of data from preclinical research. Acta Psychiatr. Scand. Suppl. 111: 14-21.
85. Torta, D.M.E. \& L. Castelli. 2008. Reward pathways in Parkinson's disease: clinical and theoretical implications. Psychiatry Clin. Neurosci. 62: 203-213.

86. Schmitz, G., B. Mohammadi, A. Hammer, et al. 2013. Observation of sonified movements engages a basal ganglia frontocortical network. BMC Neurosci. 14:1. 